\title{
Modification of slope stability probability classification and its application to rock slopes in hydropower engineering regions
}

\author{
Li Xiu-Zhena,b*, Tan Rong-Zhia,b* and Gao Yan ${ }^{c}$ \\ ${ }^{a}$ Chinese Academy of Sciences, Key Laboratory of Mountain Hazards and Earth Surface Process, 610041, Chengdu, China; (Ixzljt@imde.ac.cn) \\ ${ }^{b}$ Chinese Academy of Sciences, Institute of Mountain Hazards and Environment, 610041, Chengdu, China; (corresponding author: tanrz@imde.ac.cn / Ixzlit@imde.ac.cn) \\ c Guizhou University, College of Resources and Environment Engineering, 550025, Guiyang, China
}

doi: $10.4154 / g c .2019 .20$

Article history:

Manuscript received April 11, 2019

Revised manuscript accepted July 08, 2019

Available online December 20, 2019

Keywords: rock slopes, hydropower engineering region, slope stability probability classification system, modification, Hoek-Brown strength criterion, CSMR system

\begin{abstract}
Stability assessment of rock slopes in hydropower engineering regions is an important and complex issue. Rock mass classification systems are a good approach because they can thoroughly consider many factors influencing rock slope stability. The slope stability probability classification (SSPC) system is a novel method. However, it has two limitations when applied to rock slopes: 1) it is only suitable for slopes less than $45 \mathrm{~m}$ in height, and 2) there is great subjectivity and randomness in the estimation of intact rock strength. Therefore, this study presents two modifications of the SSPC system by adopting the Hoek-Brown strength criterion and an empirical formula for maximum slope height. Evaluation of results from of 34 typical rock slopes of the major hydropower engineering regions in China indicated that the accuracy rate of the modified SSPC for stability evaluation of these slopes was $61.8 \%$, and the accuracy for stability evaluation of 10 slopes with non-structural control failure was $80 \%$. The stability values of stable and unstable slopes obtained using the modified SSPC were different to those obtained using the Chinese Slope Mass Rating (CSMR) and modified CSMR systems. In addition, the identification accuracy rate of the modified SSPC was significantly higher than that of the CSMR and modified CSMR. Therefore, the modified SSPC can be applied to hydropower engineering regions, providing a new means of rapidly evaluating the slope stability of high rock slopes (slopes $>45$ $\mathrm{m}$ in height) in these regions.
\end{abstract}

\section{INTRODUCTION}

Slope rock mass is a type of very complex material with timespace variability. Under the natural state, the rock mass not only has a long and complicated deformation history, but also includes many crisscrossed discontinuous planes such as joints and fractures after experiencing many orogenetic and tectonic movements. It has also usually been affected over a long period by many kinds of natural factors such as weathering and rainfall, as well as construction and other man-made factors. Under complex geological conditions, it is difficult to accurately determine the spatial and temporal distribution of rock mass properties except through careful investigation and testing. Therefore, it is difficult for any kind of mechanical model to describe its mechanical behaviour in an all-round and accurate way. Pure theoretical calculation and experimental analysis often fail to solve practical problems. The problems often need geological engineers to make decisions on the base of their experience.

Because slope rock and soil mass is extremely complex, we are still far from a full and perfect understanding of its geological characteristics, deformation, strength and mechanical properties (CHEN, 2005). Therefore, the study of rock slopes is still in the process of continuous exploration and improvement based on experience. The stability assessment of rock slopes in a hydropower engineering region is especially a very important and complicated issue. At present, rock mass classification systems provide a good approach and have been widely applied in the stability assessment of rock slopes by many researchers because they can consider many geological factors that affect slope stabi- lity and obtain a quantitative empirical formula. Since the 1870s, many scholars have put forward various rock mass classification systems for rock slope stability evaluation (PANTELIDIS, 2009; RUSSELL et al., 2009; XIAO, 2007; ZHENG et al., 2016), such as Rock Mass Rating (RMR) by BIENIAWSKI (1974), Slope Mass Rating (SMR) by ROMAN (1985), Rock Mass Strength (RMS) by SELBY (1980), Slope Rock Mass Rating (SRMR) by ROBERTSON (1988), Geological Strength Index (GSI) by HOEK et al. $(1988,2002)$ and CSMR for slopes in hydropower engineering region by CHEN et al. (1997). SHI et al. (2005) proposed the Highway Slope Mass Rating (HSMR) system for rock slopes of mountain highways based on the SMR. WU et al. (2005) proposed a General Slope Mass Rating (GSMR) system applicable to the evaluation of rock slope stability based on a large number of practical engineering research projects. LI et al. (2010) proposed a modified CSMR using a continuous function to modify the systematically modify quantitative parameters in CSMR. DAFTARIBESHELI et al (2011) applied fuzzy set theory to the RMR system and presented a Fuzzy Slope Mass Rating (FSMR) system. All of these classification systems provide an important means for the rapid evaluation of rock slope stability (FRANCIONI et al., 2018; MORALES et al., 2019).

However, most of the aforementioned systems for rock slope stability classification are based on a single weight value to evaluate slope stability, and the failure mechanisms and modes of rock slopes are not strictly considered. For example, the slope stability of structural control failure is mainly affected by the structural plane condition and the relationship between the structural plane 
and slope orientation. However, the slope stability of non-structural control failure is mainly affected by the shear strength of the slope rock mass and height. In addition, the existing classification systems do not clearly distinguish an exposure rock mass and a slope rock mass, the characteristics of which may be quite different due to the influences of weathering and excavation (HACK, 2002).

Hack put forward the Slope Stability Probability Classification (SSPC) system in 1998 based on the aforementioned issues and the shortcomings of the existing slope stability classification systems (HACK, 2002; HACK et al., 2003). The SSPC system resulted in great progress in the evaluation of the stability of rock slopes. For example, the adoption of a continuous formula during the calculation process ensures non-step classification results. The stability evaluation of rock slopes has been divided into orientation-dependent stability and orientation-independent stability according to slope failure types. The evaluation result depends on the probability of slope failure in different modes, but not on a single weight value. The SSPC system has been applied and developed in the study of highway slopes in Spain for four years, and has also been applied in Austria, South Africa, New Zealand, China, and the Netherlands and has achieved good results (DAS et al., 2010; HACK et al., 2003; LI and XU, 2016; LINDSAY et al., 2000; LINDSAY et al., 2001; CANAL et al., 2016).

The empirical formula of the SSPC system is mainly based on the statistical analysis of 184 highway slopes with a slope height less than or equal to $45 \mathrm{~m}$ (HACK et al., 2003), therefore, this system may be more suitable to the stability evaluation of rock slopes with a slope height less than $45 \mathrm{~m}$. In addition, SSPC emphasizes the influence of weathering and excavation on slope stability and pays relatively little attention to the intact rock strength compared to previous slope stability classification systems. In the SSPC system, the parameter of intact rock strength is mainly estimated by field observation and a simple hammer test, which increases its subjectivity and randomness. LINDSAY et al. (2000) also noted that this estimating method of intact rock strength is the major shortcoming of the SSPC system.

The SSPC system cannot be directly used to evaluate the stability of rock slopes in a hydropower engineering region as slope heights are generally greater than $45 \mathrm{~m}$. A modified method of shear strength and maximum slope height of a rock slope in the SSPC system was proposed in this study adopting the HoekBrown strength criterion and an empirical formula of maximum slope height, based on the limitations of slope stability evaluation in the SSPC. An analysis of some case studies showed that the modified SSPC can be used for probability evaluation of rock slope stability in a hydropower engineering region and can provide a new means for rapid evaluation of rock slope stability.

\section{THE SSPC CLASSIFICATION}

\subsection{Overview}

The method considers three kinds of rock mass including exposure rock mass (ERM), reference rock mass (RRM) and the slope rock mass (SRM), obtains rock mass parameters based on investigation and testing on the slopes in the field, and identifies the possible failure mode and instability probability according to failure modes and mechanisms of the rock slopes. The ERM is the rock mass in the exposure; the RRM is the rock mass in an imaginary, unweathered, and undisturbed condition prior to excavation; and the SRM is the rock mass in which the existing or new slope is to be situated.
Compared to the SMR classification systems, the SSPC method has made great progress in the stability identification of rock slopes. The main advantages of the method include: (1) it has strong operability, and its evaluation parameters are easy to obtain in the field; (2) the continuous formulae are adopted in the calculation process, which guarantees the non-step property of the graded results; (3) evaluating orientation-independent slope stability is based on the classical slope stability analysis method, evaluating orientation-dependent slope stability embodies the controlling effect of structural surface condition and features values on the slope stability; (4) evaluation result depend on the probability values that the slope may occur in different failure modes, and does not only depend on a rating weight value such as the SMR classification systems.

\subsection{Basic theory}

The concept of the SSPC system is based on the following three aspects (HACK, 2002).

(1) A three-step classification system is introduced to describe the exposure rock mass, the reference rock mass, and the slope rock mass (Fig. 1).

(2) The slope stability is determined by the probable occurrence of different failure mechanisms instead of a single weight value.

(3) Unambiguous and simple procedures for data collection in the field.

The assessment procedure of the method can be seen in Figure 2.

\subsection{Evaluation indexes}

The evaluation indexes used in the SSPC system mainly include intact rock strength, orientation, spacing and the number of discontinuity sets, shear strength characteristics of the discontinuities.

The acquisition and quantification of intact rock strength in this classification system are mainly estimated by field observation and a simple hammer test. The relationship between the orientation of discontinuity and the orientation of slope determines the failure mechanism and failure mode of the rock slope. In the SSPC system, the influence of the discontinuity orientation on the slope stability is mainly reflected in the change in the apparent dip $(A P)$ of the structural surface. $A P$ can be calculated using the following formula:

$$
A P=\arctan \left(\cos \left(\alpha_{s}-\alpha_{j}\right) \cdot \tan \beta_{j}\right)
$$

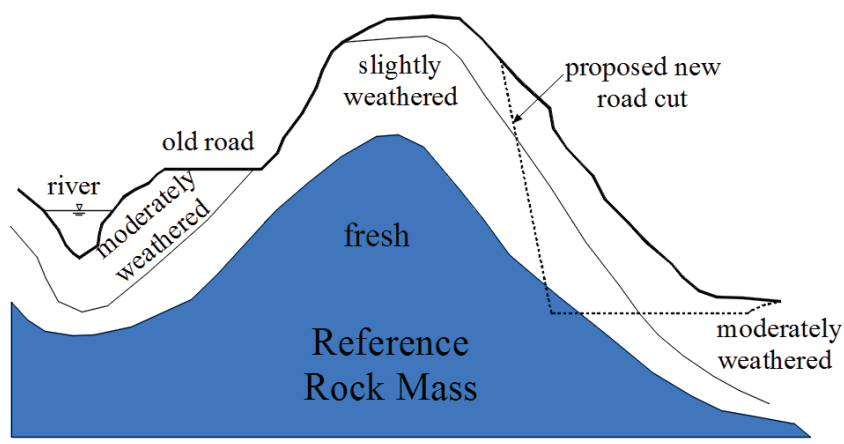

Figure 1 Sketch of exposures in rock masses of various degrees of weathering and different types of excavation indicating the concept of the 'reference rock mass' (HACK, 2003). 


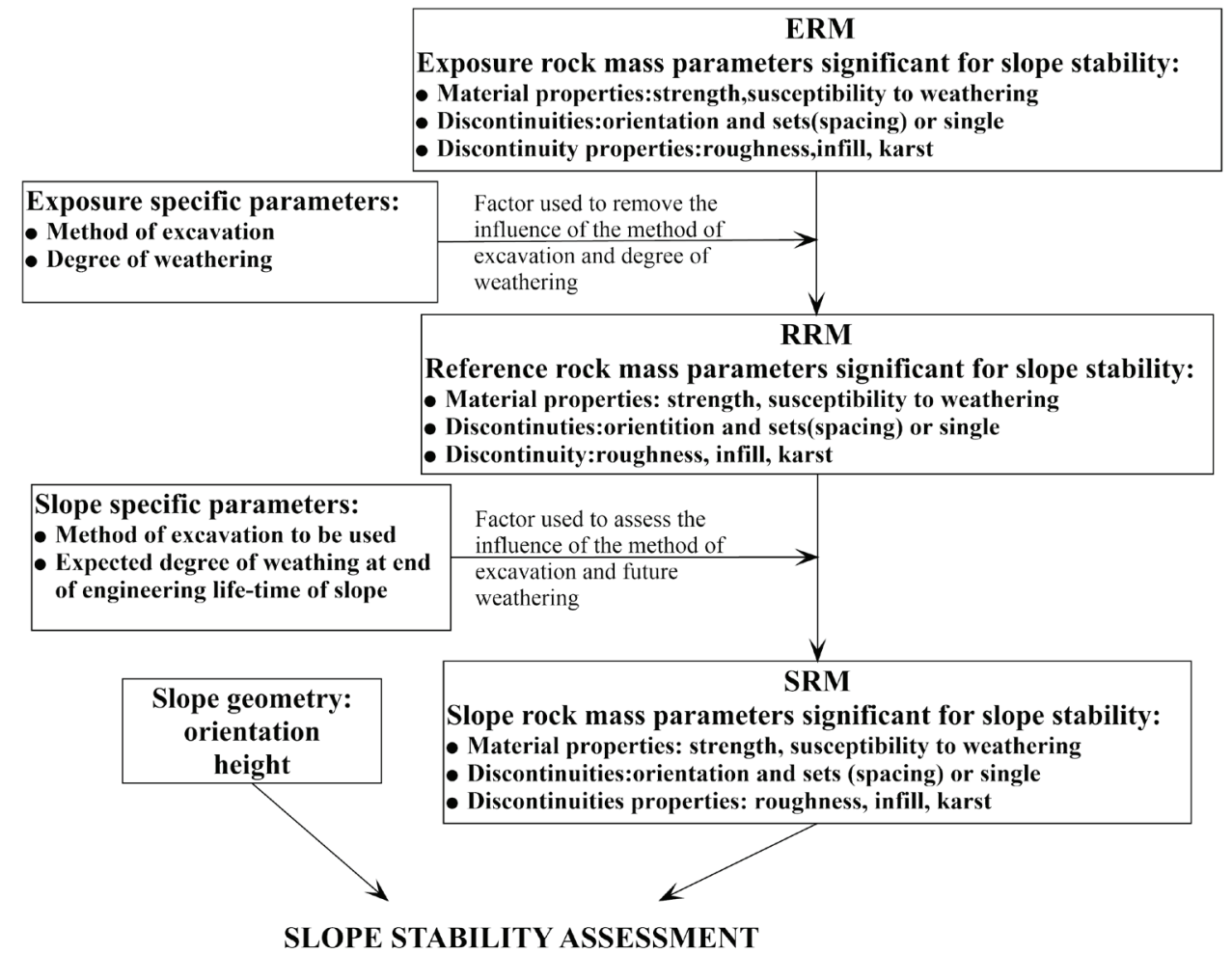

Figure 2. Flow diagram of the three-step concept of the SSPC system (HACK, 2003).

In this formula, $\alpha_{\mathrm{s}}$ is the slope direction, $\alpha_{\mathrm{j}}$ is the discontinuity dip direction, and $\beta_{\mathrm{j}}$ is the discontinuity dip angle.

In the SSPC system, the combination of the spacing and the number of discontinuities is mainly quantified by three groups of discontinuities with the smallest spacing, according to the diagrammatic method proposed by TAYLOR (1980). The conditions of the discontinuities determine their shear strength. The characteristics of the discontinuities are determined by four main factors: large-scale roughness $(R l)$, small-scale roughness $(R s)$, infill material $(\mathrm{Im})$, and karst $(\mathrm{Ka})$. A discontinuity condition factor (TC) can be determined by a multiplication of the four factors as follows:

$$
T C=R l * R s * \operatorname{Im} * K a
$$

\subsection{Evaluation rules}

The slope stability of the SSPC system is determined using two analyses according to the failure mechanism and main control factors of the rock slopes: one is related to the orientation of the discontinuities and the slope (orientation-dependent stability), and the other is unrelated to the orientation of the discontinuities and the slope (orientation-independent stability). The former is for stability analysis of rock slopes of structural control failure, while the latter is for stability analysis of rock slopes of non-structural control failure.

\section{Orientation-dependent stability assessment}

This type of slope stability analysis mainly considers the condition of discontinuity planes, the relationship between dip direction and angle of discontinuity planes and dip direction and angle of slopes. According to the failure criteria of sliding and dumping, the failure probability of the rock slope in different modes is analysed, and the maximum probability is determined as the possible failure probability and the corresponding failure mode is taken as the possible failure mode of the rock slope. For sliding failure, the SSPC system built a graph between the condition parameters of discontinuous plane and the apparent dip angle of discontinuous plane as a criterion to evaluate the stability probability of the slopes. For toppling failure, the relationship between the condition parameters of discontinuous plane and the apparent dip angle of discontinuous plane and slope angle is established as a criterion to evaluate the stability probability of slopes.

\section{Orientation-independent stability assessment}

This type of slope stability analysis adopts a linear shear plane model which follows the Mohr-Coulomb failure criterion. Firstly, by determining the cohesion and internal friction angle of the slope rock mass, the maximum stability slope height is calculated. Secondly, the ratio of the maximum stable slope height to the actual slope height and the ratio of the internal friction angle of the rock mass to the actual slope angle are calculated. Finally, according to the linear shear plane failure model, the possible failure probability of rock slopes can be obtained by means of the related figures published in HACK et al. (2003).

Detailed descriptions and related figures regarding the SSPC method are available in HACK (2002) and HACK et al. (2003).

\section{MODIFICATION OF THE SSPC FOR ROCK SLOPES IN HYDROPOWER ENGINEERING REGIONS}

\subsection{Limitations of the SSPC}

As previously mentioned, the empirical formula in the SSPC system (such as the calculation formula of shear strength and the maximum slope height of a rock mass) is mainly based on the analysis of highway slopes in Spain; thus, it is more suitable in the stability evaluation of slopes below $45 \mathrm{~m}$ in height. In addition, compared to previous slope stability probability classifica- 
Table 1. Comparison of the accuracy of the stability identification systems applied to the 34 rock slopes.

\begin{tabular}{|c|c|c|c|c|}
\hline \multicolumn{2}{|c|}{ Correct number and accuracy rate of evaluation } & CSMR system & Modified CSMR system & Modified SSPC system \\
\hline \multirow{2}{*}{34 slopes } & Correct number & 14 & 15 & 21 \\
\hline & Accuracy & $41.18 \%$ & $44.12 \%$ & $61.76 \%$ \\
\hline \multirow{2}{*}{$\begin{array}{l}10 \text { slopes of non-structural } \\
\text { control failure }\end{array}$} & Correct number & 5 & 7 & 8 \\
\hline & Accuracy & $50 \%$ & $70 \%$ & $80 \%$ \\
\hline
\end{tabular}

tion systems, the SSPC system emphasizes the influence of weathering and excavation on slope stability, while the intact rock strength is estimated via field observation and a simple hammer test. The estimation of the strength is strongly subjective in the SSPC system (LINDSAY et al., 2001).

In 2016, application of the SSPC method in the stability assessment of highway slopes in China obtained good results (LI $\&$ XU, 2016). The original plan was to use the SSPC method to assess the stability of hydropower engineering slopes. However, it was discovered that the SSPC system isn't very suitable for the slopes in hydropower regions, due to the greater height of these slopes (generally more than $45 \mathrm{~m}$ ). Based on the limitations of slope stability evaluation in the SSPC system, a modification method of shear strength and maximum slope height of rock slopes of non-structural control failure was proposed adopting the Hoek-Brown strength criterion and an empirical formula of maximum slope height, while the SSPC system was still used to evaluate the stability of the rock slope of structural control failure. The specific modification methods are described below.

\subsection{Modification of SRM strength in the SSPC}

The modification of the shear strength of the SRM of non-structural control failure is mainly based on the relatively perfect Hoek-Brown empirical strength criterion (HOEK \& BROWN, 1980, 1988; HOEK, 1990; HOEK et al., 2002). The calculation formula of parameters $c^{\prime}$ and $\varphi^{\prime}$ of the equivalent Mohr-Coulomb rock mass strength in a different range of slope height stress can be derived from the linear Mohr-Coulomb failure criterion and related rock mass parameters, including the geological strength index $(G S I)$, lithological coefficient $\left(m_{\mathrm{i}}\right)$, and the uniaxial compressive strength $\left(\sigma_{\mathrm{ci}}\right)$ (HOEK et al., 2002) as follows:

$$
\begin{gathered}
c^{\prime}=\frac{\sigma_{c i}\left[(1+2 a) s+(1-a) m_{b} \sigma_{3 n}^{\prime}\right]}{(1+a)(2+a)} \times \\
\frac{\left(s+m_{b} \sigma_{3 n}^{\prime}\right)^{a-1}}{\sqrt{1+\left(6 a m_{b}\left(s+m_{b} \sigma_{3 n}^{\prime}\right)^{a-1}\right) /((1+a)(2+a))}} \\
\varphi^{\prime}=\sin ^{-1}\left[\frac{6 a m_{b}\left(s+m_{b} \sigma_{3 n}^{\prime}\right)^{a-1}}{2(1+a)(2+a)+6 a m_{b}\left(s+m_{b} \sigma_{3 n}^{\prime}\right)^{a-1}}\right]
\end{gathered}
$$

where $\sigma_{3 n}=\sigma_{3 \max }^{\prime} / \sigma_{c i}, \sigma_{c i}$ is the uniaxial compressive strength of the rock.

$\sigma_{3 \max }^{\prime}$ is the upper limit of the stress range calculated using the Bishop method under a different slope height, and it can be obtained using the following formulas:

$$
\begin{gathered}
\frac{\sigma_{3 \max }^{\prime}}{\sigma_{c m}^{\prime}}=0.72\left(\frac{\sigma_{c m}^{\prime}}{\gamma H}\right)^{-0.91} \\
\sigma_{c m}^{\prime}=\sigma_{c i} \cdot \frac{\left(m_{b}+4 s-a\left(m_{b}-8 s\right)\right)\left(m_{b} / 4+s\right)^{a-1}}{2(1+a)(2+a)}
\end{gathered}
$$

where $\gamma$ is the bulk density of the rock mass, $m_{\mathrm{b}}$ is the material parameter of the rock mass, and $a$ and $s$ are parameters of the rock mass that can be obtained using the following formulas:

$$
\begin{gathered}
m_{b}=m_{i} \cdot \exp \left(\frac{G S I-100}{28-14 D}\right) \\
a=\frac{1}{2}+\frac{1}{6}\left(e^{-G S I / 15}-e^{-20 / 3}\right) \\
s=\exp \left(\frac{G S I-100}{9-3 D}\right)
\end{gathered}
$$

The three indexes of the rock mass; disturbance coefficient $D$, geological strength index GSI and lithological coefficient $m_{\mathrm{i}}$ in formulae (7)-(9) can be determined based on the corresponding charts in MARINOS \& HOEK (2000) and CHEN et al. (2005) which provide further detail.

\subsection{Modification of slope height in SSPC}

For a slope of non-structural control failure, HUANG (1994) calculated the critical slope of a homogeneous limited rock slope with different slope heights when the safety factor was 1 , using the equilibrium limit analysis method. The empirical formula of maximum slope height was obtained based on the known lithology, the rock mass structure, rock strength, and rock weight using a regression and nonlinear method according to the analysis results (HUANG, 1994) as follows:

$$
H_{\max }=\left(0.00651+0.00037 \times m_{i}^{1.5}\right) \times\left(\frac{\sigma_{c i}}{\gamma}\right) \times e^{G S I\left(-0.0003 \times \mathrm{m}_{\mathrm{i}}+0.0483\right)}
$$

where $H_{\max }$ is the critical height (m) representing the slope height when the tangent value of the slope angle is closer to infinity (the slope angle is near $90^{\circ}$ ), and the safety factor is equal to 1 .

The result of formula (10) better represents the real conditions of the slope (HUANG, 1994) and has been verified by engineering examples. Therefore, this formula was used to calculate the maximum slope height of the slopes in this study.

\section{PRELIMINARY APPLICATION OF THE MODIFIED SSPC TO A ROCK SLOPE IN A HYDROPOWER ENGINEERING REGION}

\subsection{Data source}

Since the 1980s, numerous high and steep slope problems have occurred in China with the construction of many important hydropower projects. CHEN (2004) took part in many scientific research projects and advisory work regarding high and steep slope problems of the projects at a national and ministerial level. CHEN and his team (2004) established a database including 115 slopes in hydropower engineering regions during his implementation of the research projects. Most of the slopes in the database have been subject to special investigation and research studies, and there are clear conclusions regarding their geometric characteristics, engi- 
neering geological characteristics, slope structure, discontinuity conditions, and stability conditions. In particular, for some of the rock slopes, there are complete and detailed stability classification indexes, such as uniaxial compressive strength, excavation methods, weathering strength, etc. Therefore, 34 slopes in hydropower engineering regions with detailed evaluation indexes in the database were used to create case studies here (Appendix Tables, Table A1).

\subsection{Process and steps}

The detailed analysis and calculation steps of the modified SSPC system are as follows:

(1) First, the lithology coefficient $m_{\mathrm{i}}$ is determined according to the type of rock slope; the value of geological strength index $G S I$ is comprehensively determined according to the rock type, weathering degree, rock mass structure and the conditions of discontinuities; the value of $D$ is determined by interpolation in the range of 0 to 1 according to the slope excavation method; and the weight $\gamma$ of different rocks is determined by referring to the relevant manual of rock mechanics and the results of laboratory tests in Chen's database previously mentioned.

(2) Second, the value of the cohesive force $c^{\prime}$ and internal friction angle $\varphi^{\prime}$ of the rock mass of different slopes is calculated using the free Roclab software (http://roclab.software.informer. $\mathrm{com} /$ ), according to the Hoek-Brown strength criterion, and based on the known intact rock strength $\sigma_{\mathrm{c}}$, geological strength index GSI, lithology coefficient $\mathrm{m}_{\mathrm{i}}$, and disturbance coefficient $D$. Then the ratio of internal friction angle and actual slope $\varphi^{\prime} / \beta_{\mathrm{s}}$ is calculated (Appendix Tables, Table A2).

(3) Third, the maximum slope height $H_{\max }$ of different slopes can be obtained according to formula (10), and the ratio of the maximum slope height of the stable slope to the real slope height is calculated (Appendix Tables, Table A2).

(4) Finally, the stability probability of the rock slope is obtained according to the value of $\varphi^{\prime} / \beta_{\mathrm{s}}$ and $H \max / H$, and referring to the original SSPC system; then, the slope stability is evaluated according to the following criteria:

When the slope stability probability $S P \leq 40 \%$, the slope is unstable;

when $40 \%<S P \leq 70 \%$, the slope is partially unstable; and

when $S P \geq 70 \%$, the slope is stable.

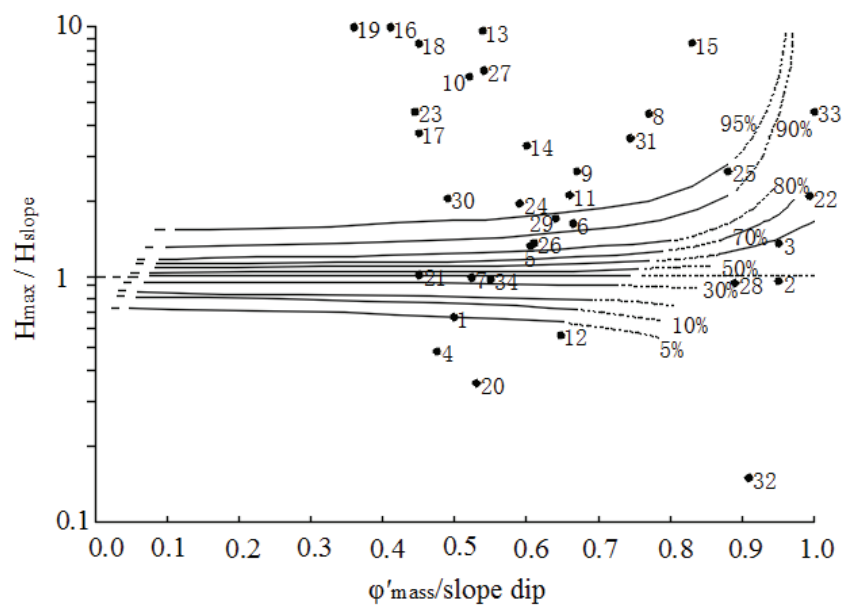

Figure 3. Distribution of 34 slopes on the probability map of orientation-independent stability using the modified SSPC system.

\subsection{Results}

Characteristic information of 34 rock slopes was extracted from the slope engineering database of China's key hydropower engineering region, which was created by CHEN (2004), such as lithology, slope structure, conditions of discontinuities, excavation method, and slope types (Appendix Tables, Table A1). The stability of the rock slopes was evaluated using the aforementioned modified SSPC system, and the evaluation results are shown in Table A2 of Appendix Tables.

Table A2 and Fig. 3 show that the evaluation accuracy rate of the 34 slopes using the modified SSPC system is $61.76 \%$ (21 are correct and 13 are incorrect). The slopes with the corresponding stability level have the largest proportion in each stability class (Fig. 4). The evaluation accuracy rate of the 10 slopes of

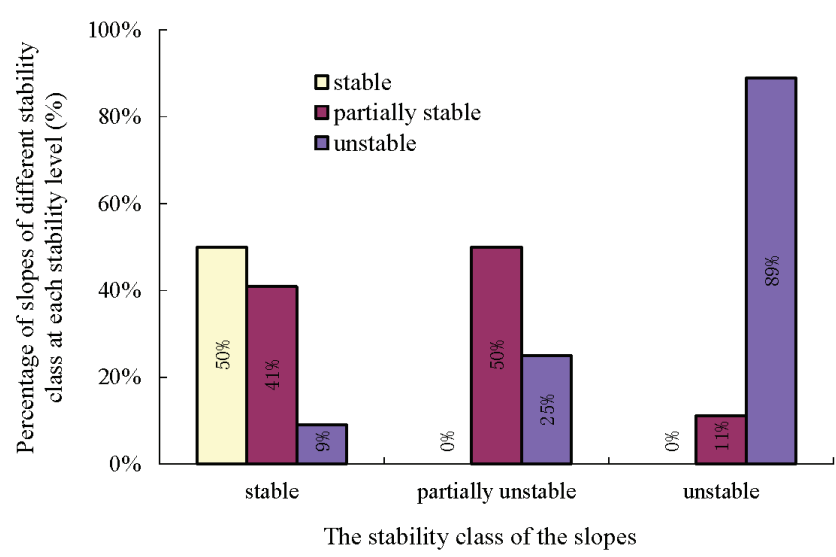

Figure 4. Percentage of slopes of different stability classes in each stability class

non-structural control failure reaches $80 \%$. Only the evaluations of the No. 2 and No. 17 slopes are incorrect, and the evaluation results of the other 8 slopes are consistent with the actual stability (Table A2).

\section{CONCLUSION AND DISCUSSION}

The SSPC system was a slope stability probability classification system proposed by HACK in 1998. Via a three-step analysis method, it considered three types of rock mass, ERM, RRM, and SRM, and analysed the failure probability in different failure modes via field investigation, calculating various parameters of rock mass, and combined with the failure mode and failure mechanism of the rock slope, evaluated the potential failure mode and failure probability. The SSPC system has resulted in great progress in the evaluation of rock slope stability compared to other classification systems. However, there are two limitations of this system: 1) it is more suitable for stability evaluation of slopes less than $45 \mathrm{~m}$ in height, and 2) there is a subjectivity in its compression strength estimation of intact rock. Therefore, the SSPC system may not be very suitable to the evaluation of rock slopes in hydropower engineering regions considering that most of the slope heights in such areas exceed $45 \mathrm{~m}$.

Based on this, a modified method of shear strength and maximum slope height of a rock slope in the SSPC system was proposed here adopting the Hoek-Brown strength criterion and an empirical formula of maximum slope height. The stability of 34 typical rock slopes in hydropower engineering regions in China was evaluated using the modified SSPC system. The evaluation results indicated that the accuracy of the modified SSPC system 


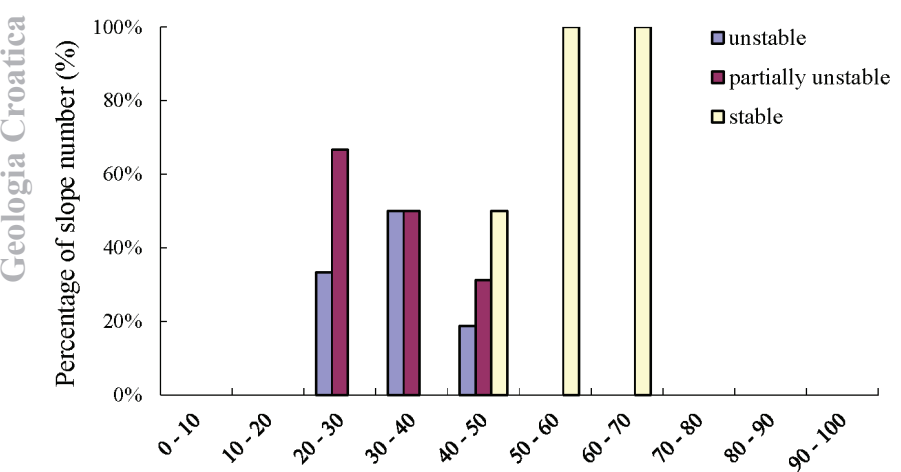

The scoring values of slopes obtained by CSMR method

(a) CSMR system

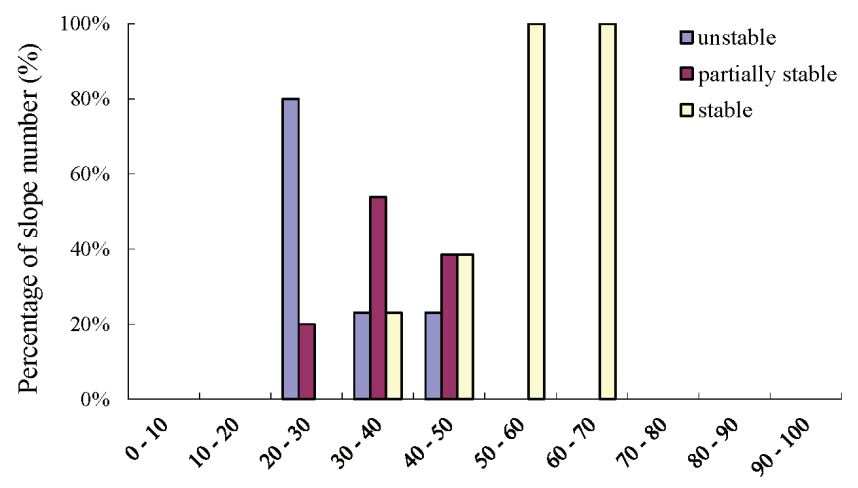

The scoring values of slopes obtained by modified CSMR method

(b) modified CSMR system

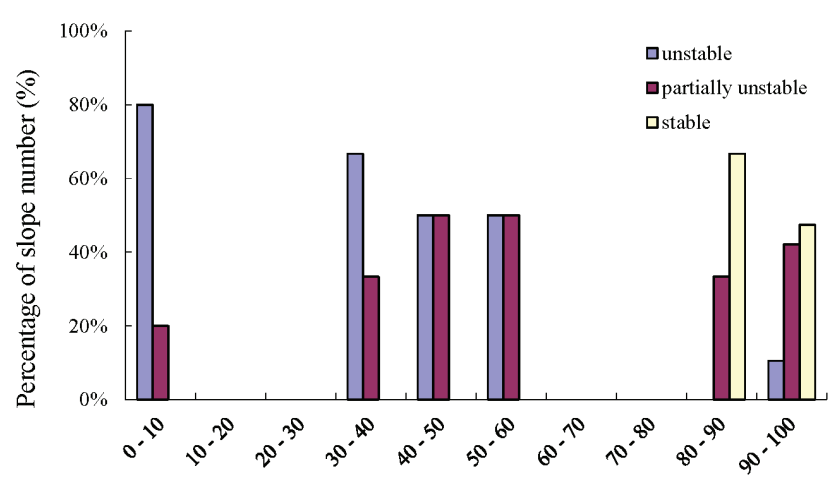

The stability probability of the slopes obtained by modified SSPC method (\%)

(c) modified SSPC system

Figure 5. Comparison of the different stability identification systems $(a-c)$ applied to the 34 rock slopes.

for stability evaluation of these slopes was $61.76 \%$ and the accuracy for stability evaluation of 10 slopes of non-structural control failure was $80 \%$ (Table 1 ).

To further compare the application effectiveness of the modified SSPC system, the stability of the aforementioned 34 rock slopes was completed grading the evaluation based on the CSMR system put forward by CHEN et al. (1997) and the modified CSMR system put forward by LI et al. (2010). More details on these two methods are available in CHEN et al. (1997) and LI et al. (2010). The evaluation results are shown in Fig. 5 and Table 1.

Table 1. shows that the value differences of slope stability evaluation obtained using the CSMR and modified CSMR systems are not significant, while the probability values of slope stability obtained using the modified SSPC system are significantly different. Slopes with different degrees of slope stability degree can be better separated (HACK et al., 2002). Moreover, the identification accuracy rate of the modified SSPC system is obviously higher than that of the CSMR and modified CSMR systems (Table 1).

Therefore, the modified SSPC system can be applied to stability probability classification of rock slopes in a hydropower engineering region. It can provide a new effective means for the rapid stability evaluation of rock slopes in a hydropower engineering region with heights exceeding $45 \mathrm{~m}$.

However, it should be noted that the stability evaluation of structural control slopes in this study cannot further calculate and validate analysis since the field investigation data of the 34 slopes in the database are neither very detailed nor complete, particularly the occurrence, number and spacing of discontinuities. In practice, according to the SSPC system, the analysis of orientation-dependent and orientation-independent stability should both be conducted and the lesser probability be taken as the final assessment result for a rock slope.

\section{ACKNOWLEDGMENT}

This research was supported by the National Key Basic Research Program of China (No. 2015CB452704), Natural Science Foundation of China (No.Y8K1200200), and the open foundation of the State Key Laboratory of Geohazard Prevention and Geoenvironment Protection (SKLGP2013K023). In particular, I would like to thank academician CHEN ZUYU and Professor WANG YUJIE of the China Water Resources \& Hydropower Science Research Institute for providing the slope database for the water conservancy and hydropower projects used in this study.

\section{REFERENCES}

BIENIAWSKI, Z.T. (1973): Engineering classification of jointed rock masses.- The Civil Engineer in South Africa, 15/12, 343-353.

CANAL,A. \& AKIN, M. (2016): Assessment of rock slope stability by probabilistic-based slope stability probability classification method along highway cut slopes in Adilcevaz-Bitlis (Turkey).- Journal of Mountain Science, 13/11, 1893-1909. doi: 10.1007/s11629-016-3954-y

CHEN, Z.Y., WANG, X.G., YANG. J., JIA, Z.X. \& WANG, Y.J. (2005): Rock slope stability analysis: principle, method, and procedure.-Beijing: China Water Power Press (in Chinese)

DAFTARIBESHELI, A., ATAEI, M. \& SERESHKI, F. (2011): Assessment of rock slope stability using the Fuzzy Slope Mass Rating (FSMR) system.- Applied Soft Computing, 11/8, 4465-4473. doi: 10.1016/j.asoc.2011.08.032

DAS, I., SAHOO, S., WESTEN, C.V., STEIN, A. \& HACK, R. (2010): Landslide susceptibility assessment using logistic regression and its comparison with a rock mass classification system, along a road section in the Northern Himalayas (India).- Geomorphology, 114/4, 627-637. doi: 10.1016/j.geomorph.2009.09.023

FRANCIONI, M., STEAD, D., SCIARRA, N. \& CALAMITA, F. (2018): Anew approach for defining Slope Mass Rating in heterogeneous sedimentary rocks using a combined remote sensing GIS approach.- Bulletin of Engineering Geology and the Environment, 1-22. doi: 10.1007/s10064-018-1396-1

HACK, R. (2002): An evaluation of slope stability classification.- In: Proceedings of the Eurock, Portugal, 3-22.

HACK, R. \& PRICE, D. (1993): A rock mass classification system for the design and safety analysis of slopes.- Eurock, 803-810.

HACK, R., PRICE, D. \& RENGERS, N. (2003): A new approach to rock slope stability - a probability classification (SSPC).- Bulletin of Engineering Geology and the Environment, 62, 167-184

HOEK, E. (1990): Estimating Mohr-Coulomb friction and cohesion values from the HoekBrown failure criterion.- International Journal of Rock Mechanics \& Mining Sciences \& Geomechanics, 27/3, 227-229.

HOEK, E. \& BROWN, E.T. (1980): Empirical strength criterion for rock masses.- Journal of Geotechnical and Geoenvironmental Engineering, 106/15715, 1013-1035.

HOEK, E. \& BROWN, E.T. (1988): The Hoek-Brown failure criterion - a 1988 update.Journal of Heuristics, 16/2, 167-188.

HOEK, E., CARRANZA-TORRES, C. \& CORKUM, B. (2002): Hoek-Brown failure criterion-2002 edition.- In: Proceedings of the Fifth North American Rock Mechanics Symposium, Toronto, 1-6. 
HUANG, G.X. (1994) A proposed susceptibility-index and influence zone of rock avalanche.- Dissertation, National Central University (in Chinese).

LI, X.Z., KONG, J.M. \& WANG, C. (2010): Modification of rock slope stability classification systems by continuous functions and its application.- Chinese Journal of Rock Mechanics and Engineering, 29/Supp.1, 3439-3446 (in Chinese).

LI, X.Z. \& XU, Q. (2016): Application of the SSPC method in the stability assessment of highway rock slopes in the Yunnan province of China.- Bulletin of Engineering Geology and the Environment, 75/2, 551-562.

LINDSAY, P., ANDERSON, J., BOURKE, F., CAMPBELL, R.N. \& CLARKE, L. (2000): Predicting slope stability in open pit gold and coal mines.- In: New Zealand Minerals and Mining Conference Proceedings, New Zealand, 29-31.

LINDSAY, P., CAMPBELL, R.N., FERGUSSON, D.A., GILLARD, G.R. \& MOORE, T.A. (2001): Slope stability probability classification, Waikato Coal Measures, New Zealand.- International Journal of Coal Geology, 45/2, 127-145. doi: 10.1016/S0166-5162(00)00028-8

LYSANDROS, P. (2009): Rock slope stability assessment through rock mass classification systems.- International Journal of Rock Mechanics and Mining Sciences, 46, 315-325.

MARINOS, P. \& HOEK, E. (2000): A geologically friendly tool for rock mass strength estimation. In: Proceeding on Geotechnical and Geological Engineering (GeoEng2000, Melbourne, Australian).

MORALES, M., PANTHI, K.K. \& BOTSIALAS, K. (2019): Slope stability assessment of an open pit mine using three-dimensional rock mass modelling.- Bulletin of Engineering Geology and the Environment, 78/2, 1249-1264.
ROBERTSON, A.M. (1988): Estimating weak rock strength.- In: Proceedings of the SME Annual Meeting, Phoenix, Arizona, 1-5.

ROCLAB software (http://roclab.software.informer.com/)

ROMAN, M. (1985): New adjustment ratings for application of Bieniawski classification to slopes.- In: Proceedings of the International Symposium on Role of Rock Mechanics, Zacatecas, Mexico, 49-53.

RUSSELL, C.P., SANTI, P.M. \& HUMPHREY, J.D. (2009): Modification and statistical analysis of the Colorado rockfall hazard rating system.- Engineering Geology, 104/1, 55-65.

SELBY, M.J. (1980): A rock mass strength classification for geomorphic purposes: with tests from Antarctica and New Zealand.-Zeitschrift für Geomorphologie, 24, 31-51.

SHI, Y.C., WANG, Z.W., WAN, G.R., WANG, Z.Y., CHEN, Q.Y. \& TANG, S.C. (2005): Study of mountain highway slope mass rating.- Chinese Journal of Rock Mechanics Engineering, 24/6, 939-944.

TAYLOR, H.W. (1980): A geomechanics classification applied to mining problems in the Shabanie and King mines, Zimbabwe.- Dissertation, University of Rhodesia.

WU, D.B. \& XU, W.Y. (2005): GSMR method for determining rock slope mechanical parameters.- Rock and Soil Mechanics, 26/9, 1421-1426.

XIAO, G.F. (2007): Study on classification method of rock slope stability in highway construction in mountainous region.- Dissertation, Institute of Rock and Soil Mechanical, the Chinese Academy of Sciences (in Chinese).

ZHENG, J., ZHAO, Y., LÜ, Q., DENG, J., PAN, X. \& LI, Y. (2016): A discussion on the adjustment parameters of the slope mass rating (SMR) system for rock slopes. - Engineering Geology, 206, 42-49. doi: 10.1016/j.enggeo.2016.03.007 


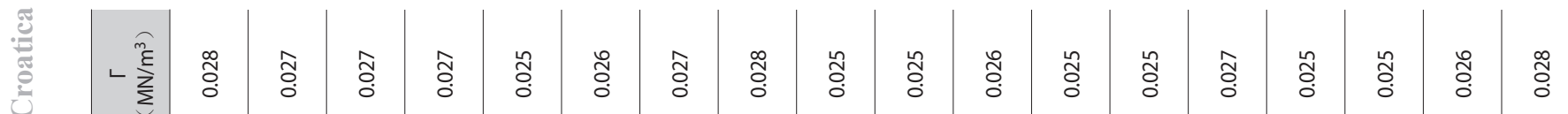

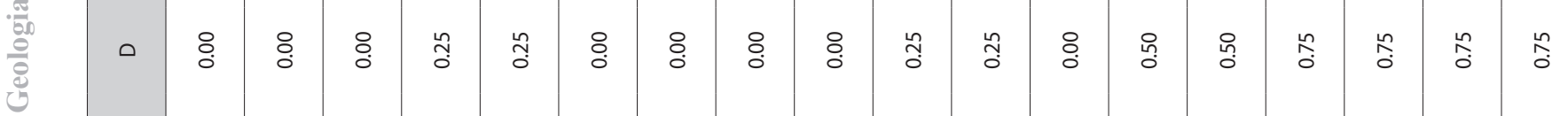

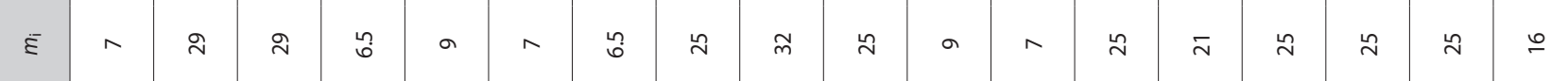
⿹ु

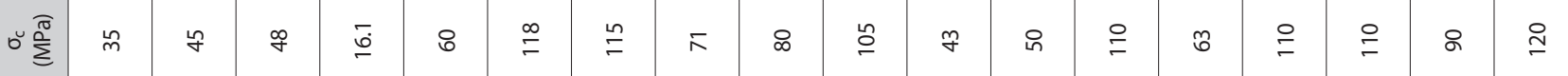

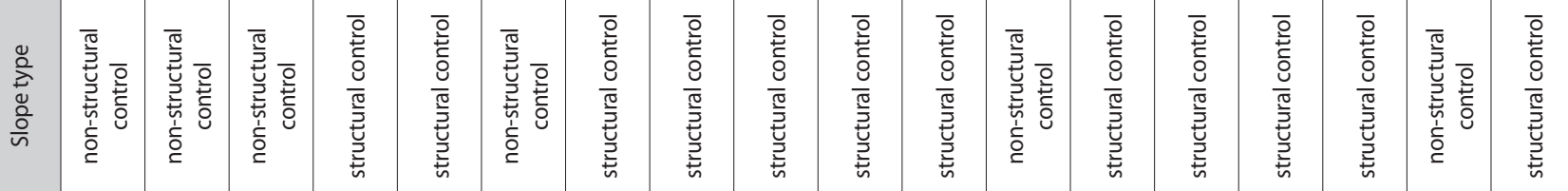

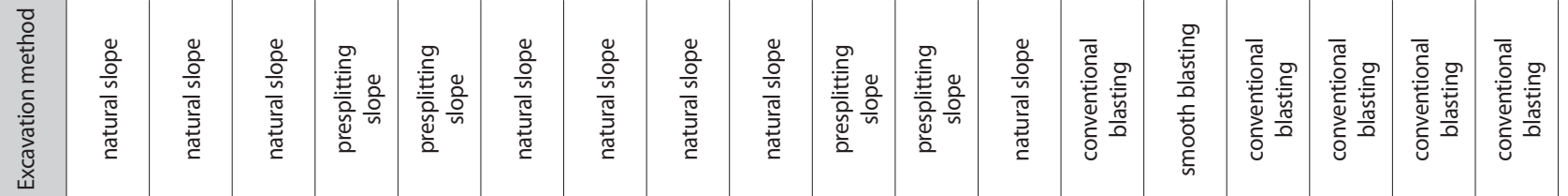

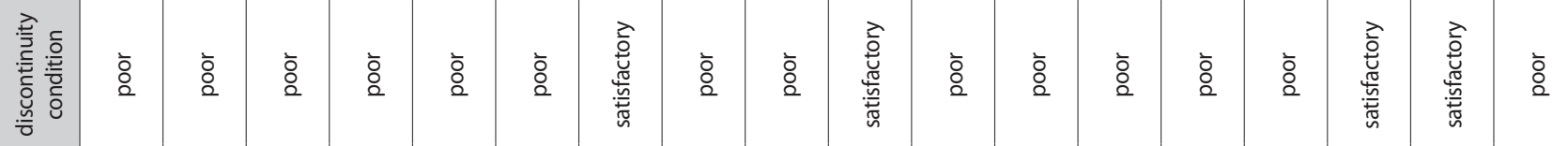

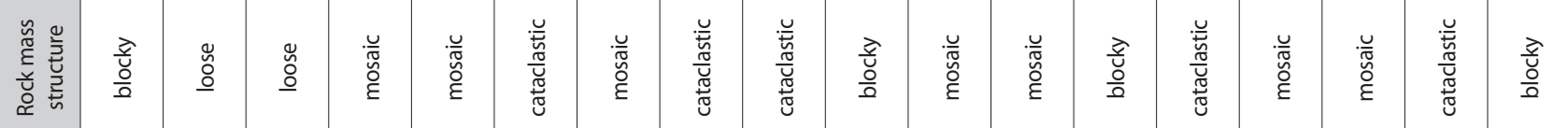

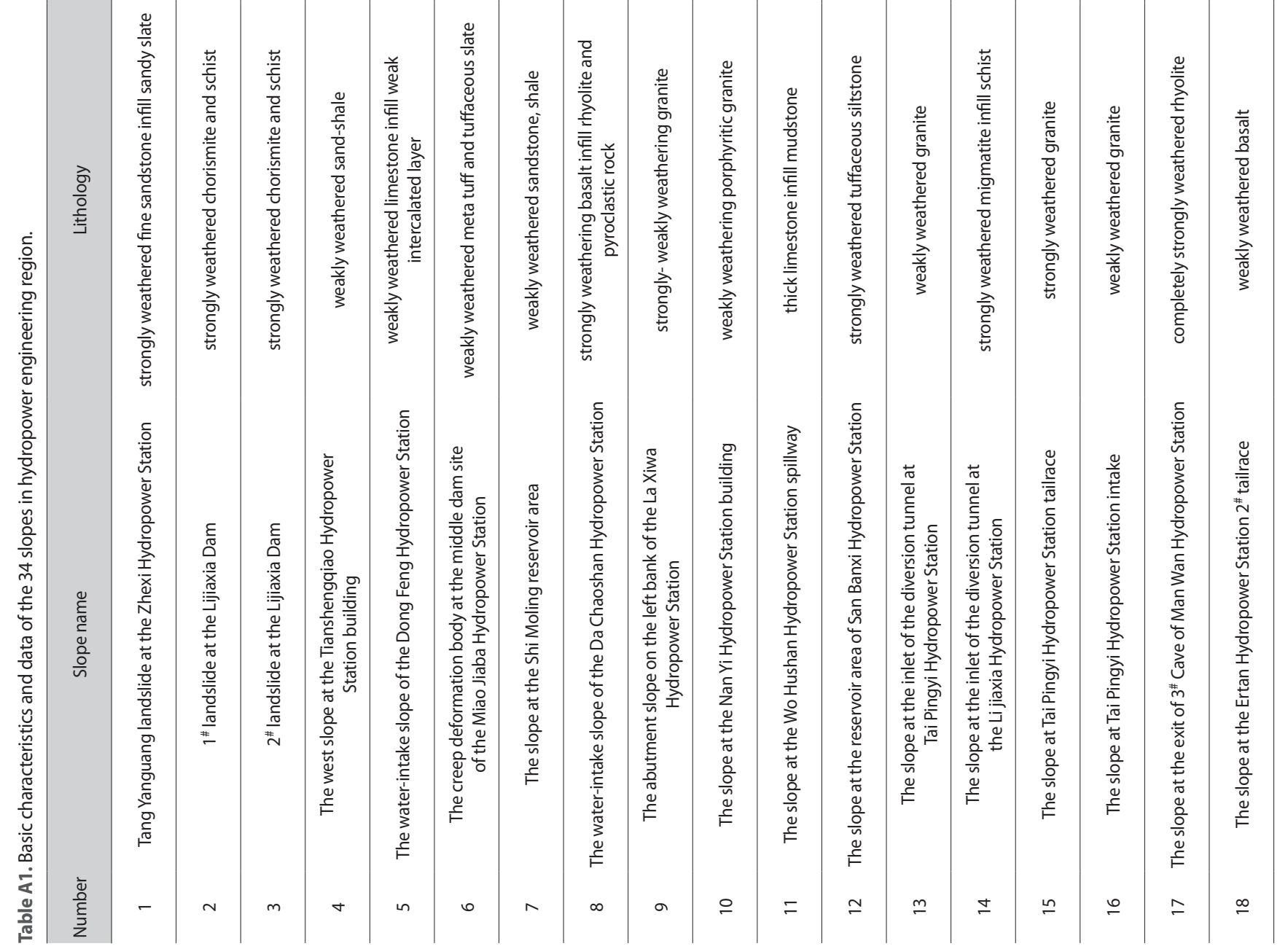




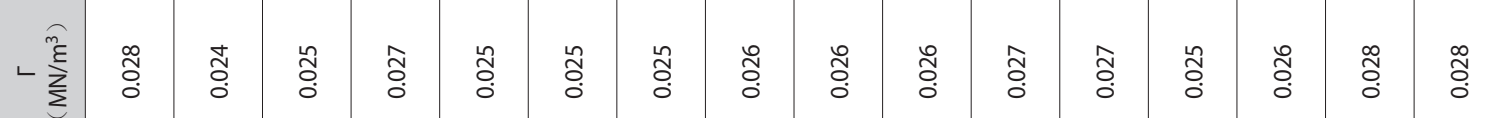

○

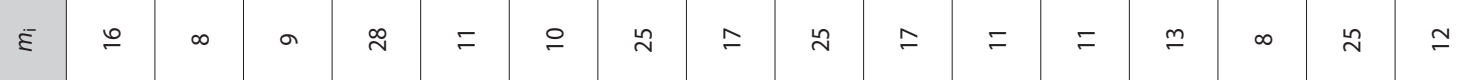

ธुॅ \&

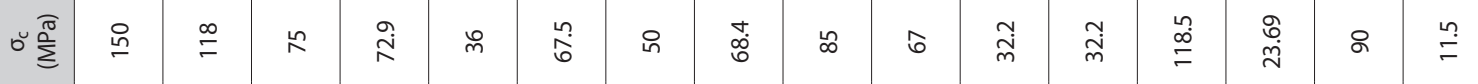

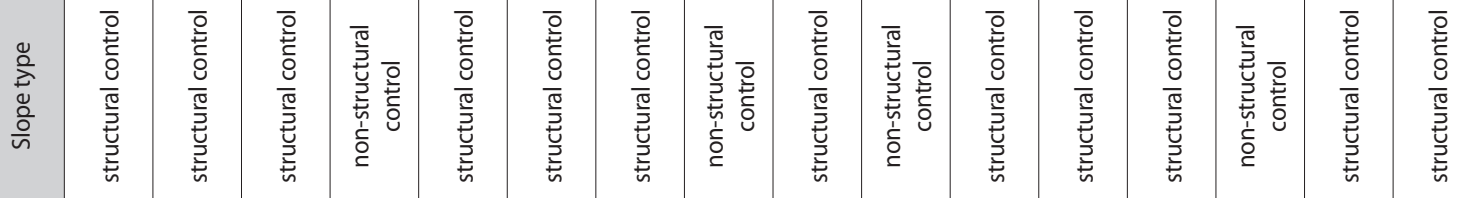

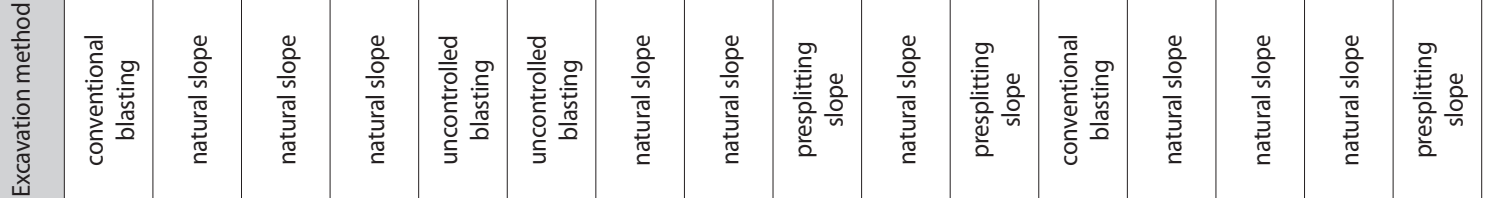

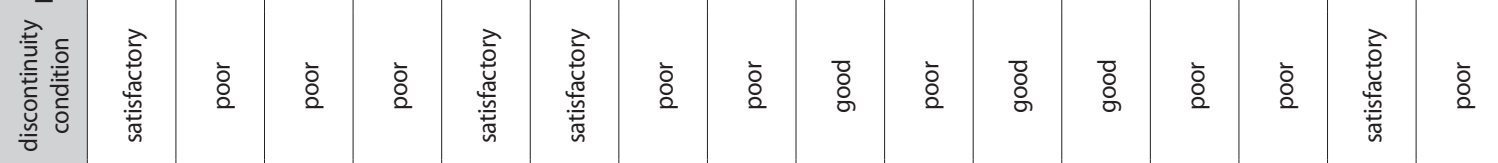

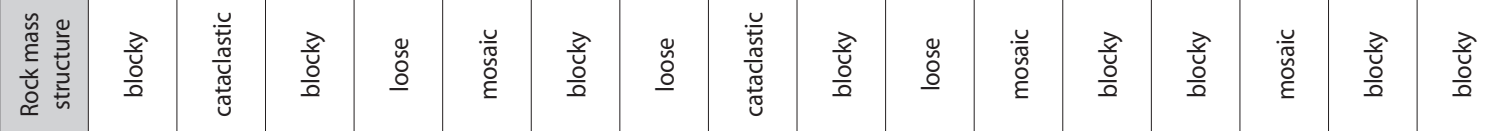

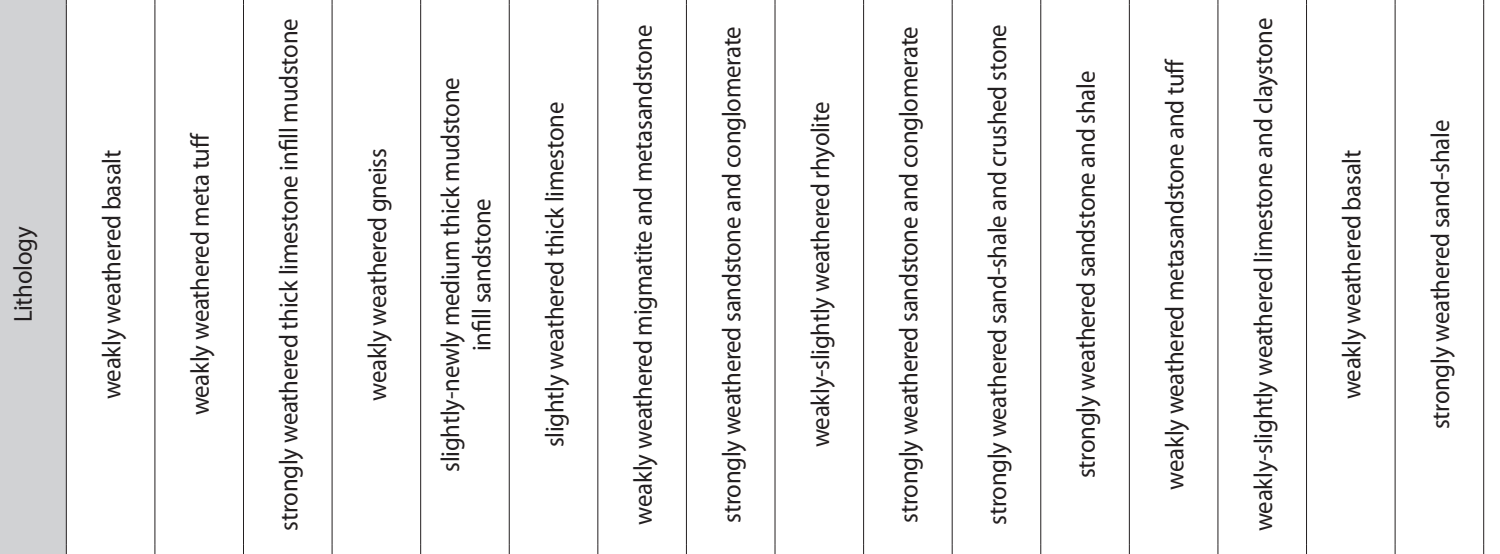

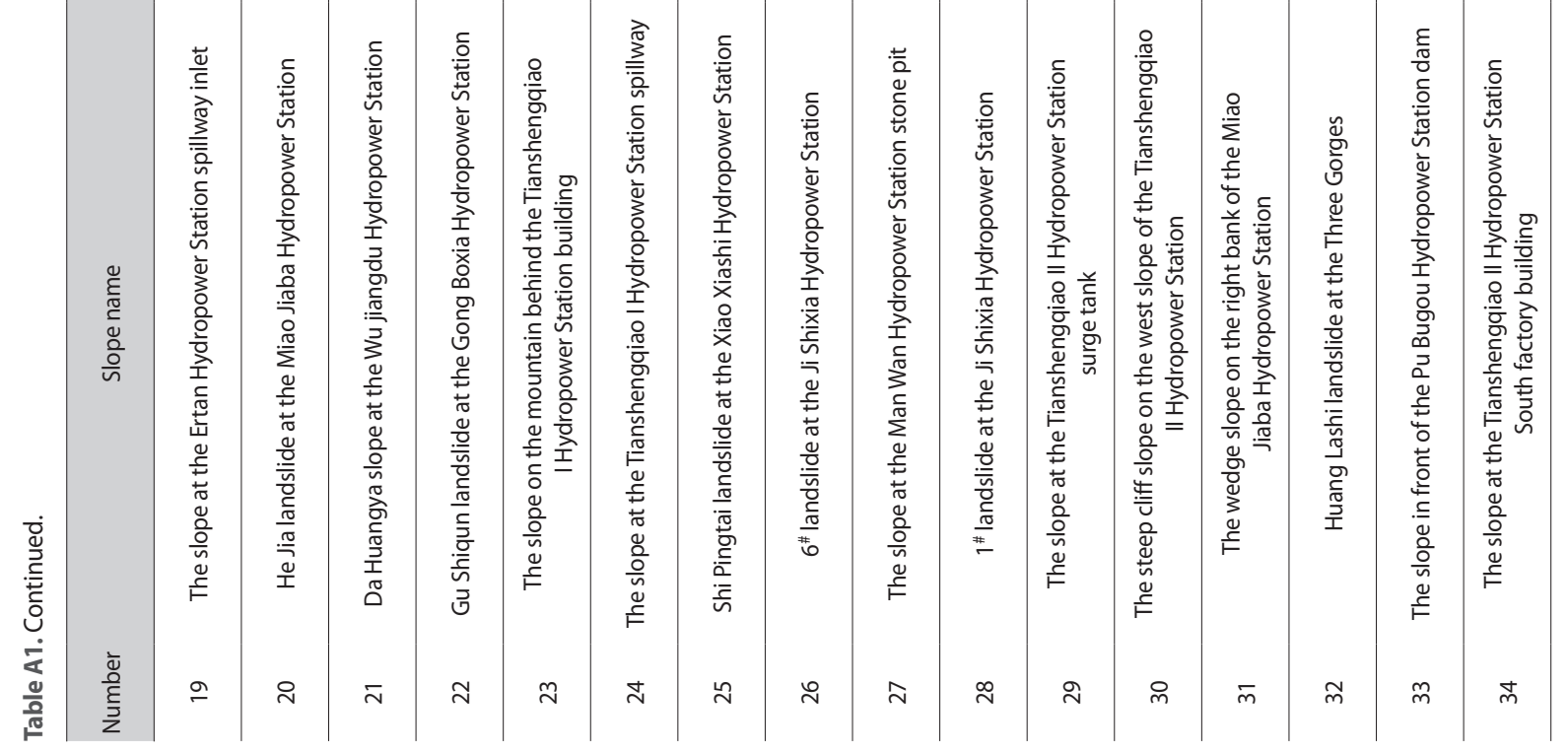




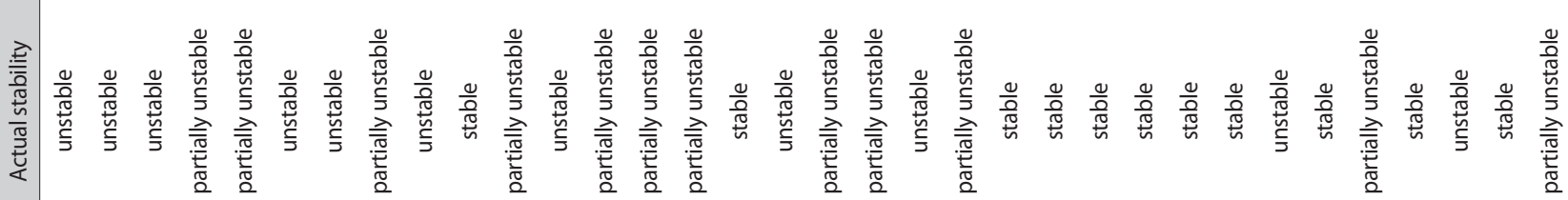

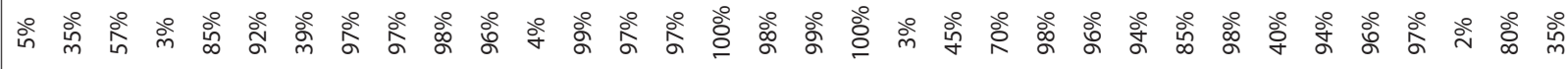

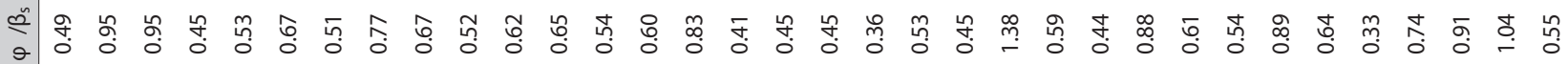

商

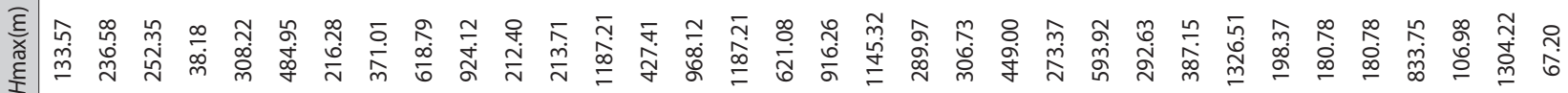

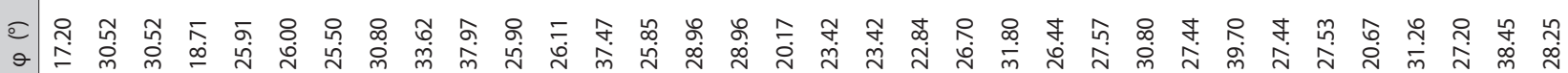

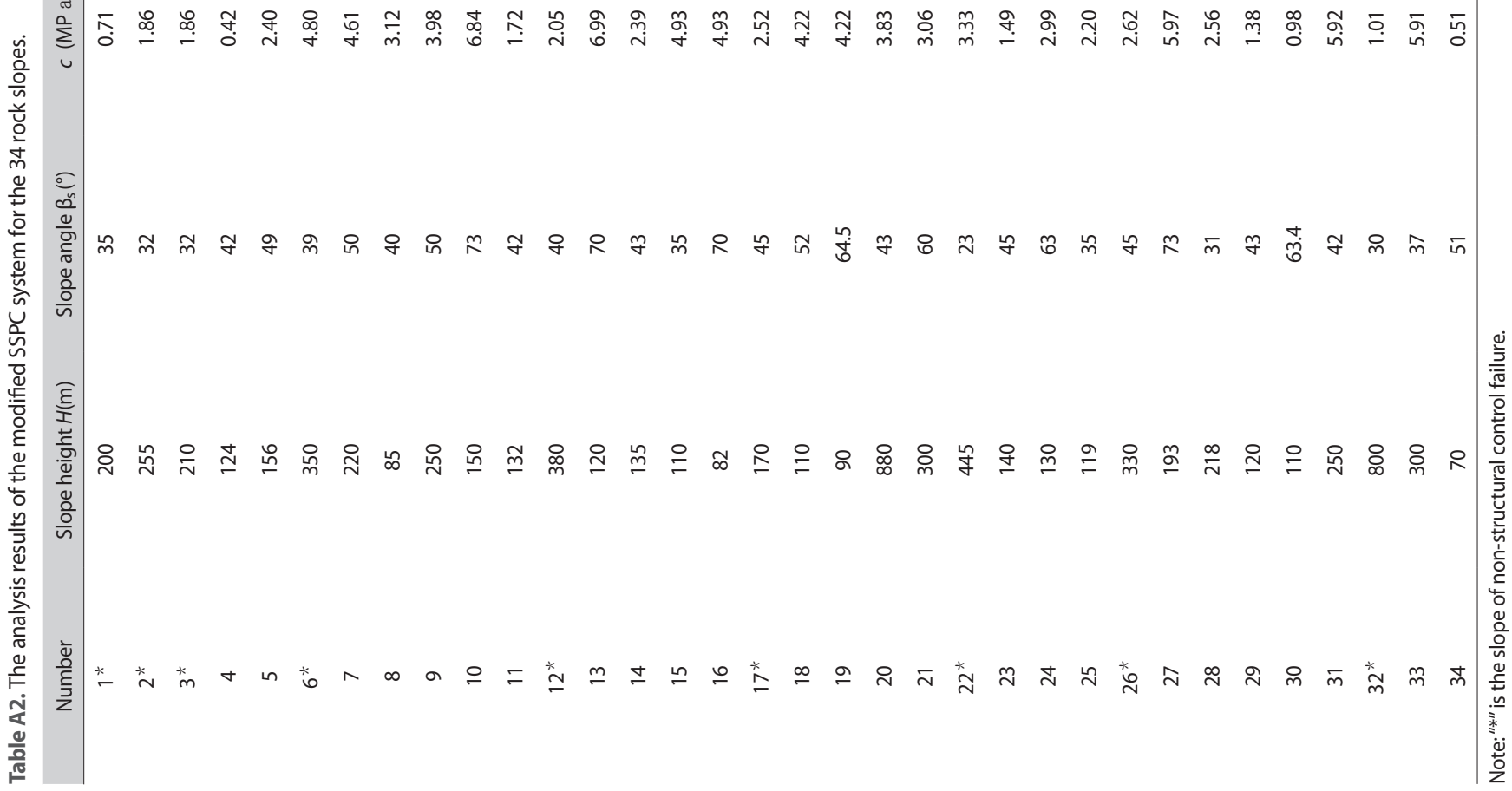

